\title{
REFLECTIONS AND PERSPECTIVES ON BIOSIMILARS IN BRAZIL
}

\author{
RENATA LUZES ARAUJ0", GABRIELA BITTENCOURT GONZALEZ MOSEGUI²*, CID MANSO D. E. MELLO VIANNA', \\ FERNANDO ANTONANZAS VILLAR ${ }^{3}$, THAIS PEREIRA CATAO 4
}

${ }^{1}$ Social Medicine Institute (Instituto de Medicina Social), Rio de Janeiro State University (Universidade do Estado do Rio de Janeiro-UERJ),

Brazil, ${ }^{2}$ Community Health Institute (Instituto de Saude da Comunidade), Fluminense Federal University (Universidade Federal

Fluminense UFF), Brazil, ${ }^{3}$ Department of Economy and Company, Economy Faculty, University of La Rioja, Logrono, La Rioja, Spain, ${ }^{4}$ Pharmacy Faculty, Fluminense Federal University (Universidade Federal Fluminense UFF), Brazil

Email: gabrielamosegui@uol.com.br

Received: 14 Apr 2020, Revised and Accepted: 16 May 2020

\section{ABSTRACT}

Objective: Biological agents are among the medicines with the highest revenue in the world market. Biosimilars are copies of biological products introduced into the market to offer clinical efficacy like the originator or reference product at lower prices. This study aimed to verify the characteristics and price differences between biological medicines registered and marketed in Brazil until the end of 2019.

Methods: All records were collected by November 2019 on the website of the National Health Surveillance Agency (Anvisa). The list of the Chamber of Regulation of the Medicines Market (CMED) consulted for the price analysis, has an economic classificatory criterion with eight ranges. Categorization, according to the date/period of authorization for marketing, was also made.

Results: At Anvisa site, there are 144 drugs present in 277 products distributed in three regulatory categories: new, biological, and similar. Approximately $73 \%$ of drugs have been approved in the past five years. Three classes represent $77.9 \%$ of all drugs-antineoplastics and immunomodulatory agents (38.6\%), blood and blood organ forming (20.7\%), and alimentary tract and metabolism (18.6\%). Of the 178 products listed in the CMED, 26 (14.6\%) have prices above 10,000 reais.

Conclusion: The prices of original products, for most of the inputs, are lower than those of biosimilars, reversing the international logic.

Keywords: Biological products, Drug price, Access to essential medicines, Health technologies

(c) 2020 The Authors. Published by Innovare Academic Sciences Pvt Ltd. This is an open access article under the CC BY license (http://creativecommons.org/licenses/by/4.0/) DOI: http://dx.doi.org/10.22159/ijpps.2020v12i7.37903. Journal homepage: https://innovareacademics.in/journals/index.php/ijpps

\section{INTRODUCTION}

Just over twenty years ago, biological or biopharmaceutical medicines revolutionized the treatment of numerous diseases, including severe chronic conditions, such as diabetes, autoimmune diseases, hematological diseases, and cancer $[1,2]$. These agents have an intrinsic complexity that relates to differentiated research and development (R and $\mathrm{D}$ ) and manufacturing processes that are difficult to execute, as they are dependent on living organisms [3]. They are also associated with specific regulatory processes and extensive clinical applicability in the treatment of complex diseases [4-6]. Although effective, their high R and D and production costs limit their access and use, especially in emerging countries, where they can pose a threat to the sustainability of health systems $[2,7]$.

In this market, biosimilars are not identical copies of the original biological medicine, although they do not present a significant difference in efficacy and safety [8-10]. The international price reduction, which, on average, does not exceed 30\% [11-13], can ease pressure on the health budget by facilitating patients' access to innovative treatments [2].

Currently, biological agents are the fastest-growing segment in spending on medicines [14]. In Brazil, in 2017, the revenue of the companies that sold them was $\mathrm{R} \$ 15,409,519,216$ or USD $491,707,322$ [15]. As there are almost no data available on the drug market in the country, there is unknown about the sales of reference and biosimilar products, whether the latter are gaining ground and have contributed to reducing treatment costs.

The impact of a biosimilar policy to increase competition in the pharmaceutical market merits assessment because it would make it possible to reduce reference prices. Understanding the profile of biological medicines registered in Brazil would allow us to estimate the evolution of this market and the challenges to be faced, and it would raise questions for the development and regulatory evaluation of subsequent versions of these products and biosimilars [16].

In this sense, the present study aimed to analyze the characteristics and price differences between biological medicines marketed in Brazil until the end of 2019, updating and providing new information on the maturation of this market in the country.

\section{MATERIALS AND METHODS}

Resolution RDC $\mathrm{n} 55^{\circ}$ of November 16, 2010, of the National Health Surveillance Agency (Anvisa), defines drugs whose molecule with known biological activity is already registered in Brazil as non-new biological products and those not yet registered in Brazil as new biological products. This classification does not follow the use of the biological reference and biosimilar terms most commonly used in scientific literature and in clinical guidelines, which causes some confusion [17]. The non-adoption of the term biosimilar, according to Interfama [18], occurs because the regulatory agency does not believe that biosimilarity is a precondition for the copy of a biological product to be registered.

In this context, in RDC $\mathrm{n}{ }^{\circ} 55 / 2010$, there are two regulatory channels for the approval and registration of biological medicines. One, regardless of the exercise of comparability, is called an "individual development path". In it, copies that have studies of noninferiority and that demonstrate, in addition to the therapeutic activity, the safety of the medicine can be authorized [17, 18]. Organic products (not new) that are approved are enabled by submitting a reduced dossier [11], being, in fact, non-biosimilar options, as they have not undergone the exercise of comparability. The second called the "path of comparability", corresponds, in theory, to the international biosimilar category. This is because comparability in terms of quality, efficacy and safety is carried out 
with registered biological products that have not necessarily passed similar tests [17].

The sample was limited to biological products registered in Brazil. Market availability was analyzed by consulting valid authorization records on the Anvisa portal [19], using the filter "biological medicines." For each product, the "reference drugs" field showed its approval for comparability, if present, and for individual development, if absent, and indicating whether the product is new or biological [17]. Information on therapeutic class and indication was completed through individual consultation of each product on the same website, carried out between 20 and 26 November 2019 . There was no filter for the initial registration date.

A first list of 346 products was established. One drug was withdrawn for having its registration canceled and another for having expired registration, yielding 344 products in the sample. Then, drugs with the same active ingredient but registered in another regulatory category were included. By individual search in the system, 56 more drugs were added, 24 in the new category, 17 in a similar category, and 15 without specification. Drug combinations were excluded, as were vaccines, serums, allergens and immunoglobulins used for the prophylaxis of some diseases (e. g., human hepatitis B immunoglobulin). The initial sample with 344 products became 277 medicines.

The drugs were analyzed according to different perspectives. The classification used the therapeutic class detailed on the Anvisa page, and the Anatomical Therapeutical Chemical (ATC) system, where medicines are divided into different groups, according to the organ or system in which they work and their chemical properties, pharmacological and therapeutic [20]. For the price analysis, the value of the cheapest presentation of the price lists of the Medicines Market Regulation Chamber (CMED) was taken [21]. The standard established was the maximum consumer price (PMC), referring to the $18 \%$ tax on the circulation of goods and the provision of services.
A classificatory economic criterion was used, where 8 price ranges were established-up to 200.00 reais, between 200 and 500.00 ; 500 $1,000.00 ; \quad 1,000-3,000.00 ; \quad 3,000-10,000.00 ; \quad 10,000-50,000.00$ $50,000-150,000.00$ and above $150,000.00$ reais. Classification according to the date/period authorization for marketing was also granted (from 1988 to 1998, between 1999 and 2009, 2010 and 2014 and 2015 to 2019).

This study did not require approval from the institutional review board or informed consent because it is based on public data and does not involve patient records.

\section{RESULTS}

The sample consisted of 144 drugs present in 277 drugs, distributed in the following regulatory categories: 24 new, 221 biologicals, 17 similar, and 15 with absent classification. Among the biologicals, 13 (5.9\%) noted their reference drugs; that is, they had their registration via comparability. Because biological products registered by this alternative are similar to biosimilars but do not have this denomination in the country, it is only possible to identify them by analyzing their dossier or, if they appear in the search on Anvisa's webpage, the name of the original medicines with which they are comparable. We take the example of etanercept. In Anvisa's database, there are three manufacturing companies and three products, each classified in a different regulatory category. One is a biological manufactured in an official laboratory, another has no described category, but it is internationally known as the original product, and the third is categorized as biological, informing its reference medicine. The latter is similar to a biosimilar (biological registered via comparator), and there are 13 other agents like it in the database.

When classified according to the first level of the ATC, five products were not classified: nimotuzumab, phosphatidylserine, dialyzable polypeptide of leukocyte extract, and two whose active ingredient was Saccharomyces cerevisiae. The rest are listed in the table below.

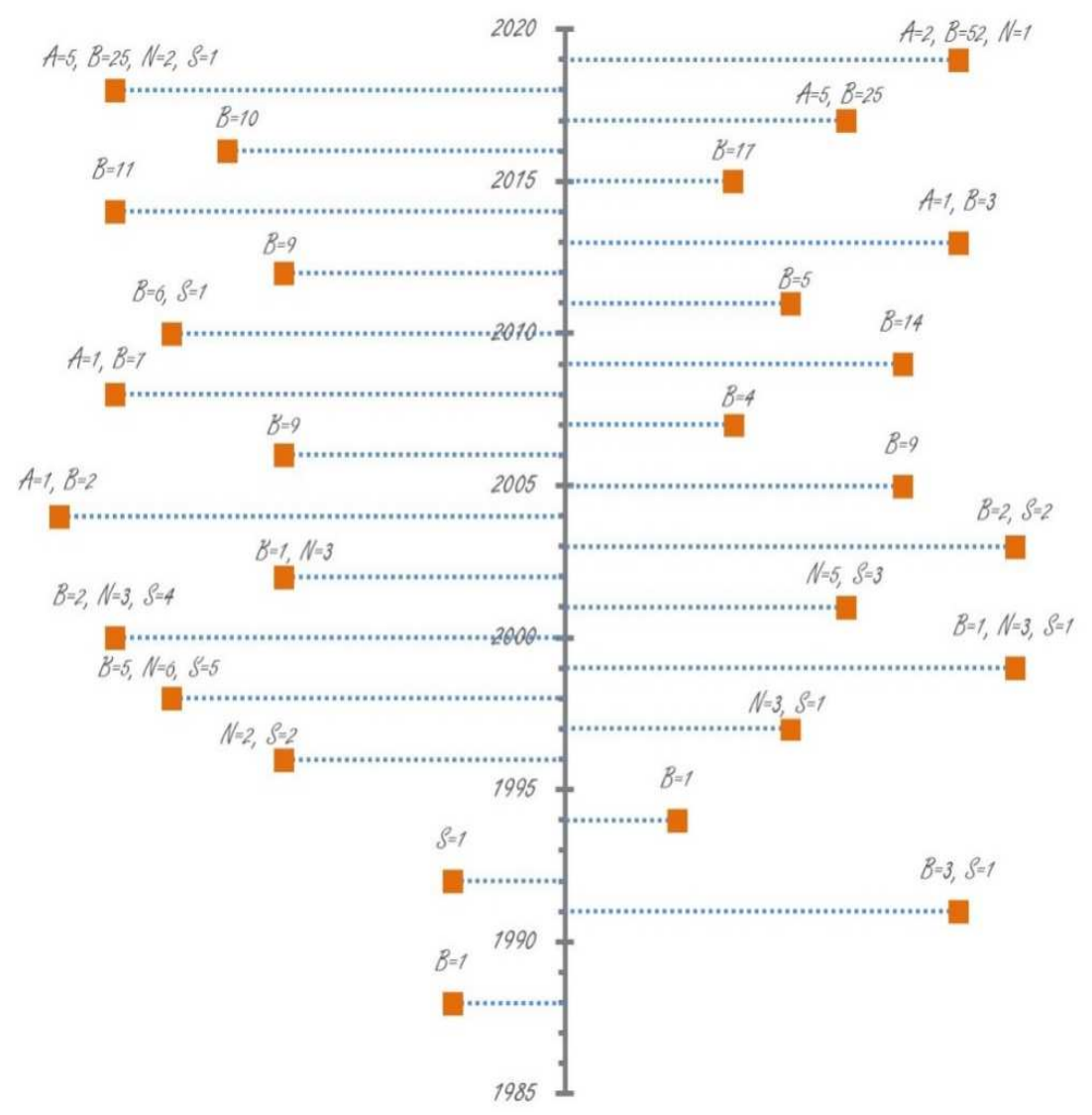

Fig. 1: Timeline of biological and biosimilar drug authorizations in Brazil Source: Author's elaboration. Legend: A: Absent; B=Biological; N: New; S: Similar 
Table 1: Number of biological drugs and pharmaceutical presentations registered with Anvisa according to ATC classification, 1988-2019

\begin{tabular}{|c|c|c|c|c|c|c|c|c|c|c|}
\hline \multirow[b]{2}{*}{ ATC first level classification } & \multicolumn{2}{|c|}{ 1988-1998 } & \multicolumn{2}{|c|}{ 1999-2009 } & \multicolumn{2}{|c|}{ 2010-2014 } & \multicolumn{2}{|c|}{ 2015-2019 } & \multicolumn{2}{|c|}{ 1988-2019 } \\
\hline & $\mathrm{D}$ & $\mathrm{P}$ & $\mathrm{D}$ & $\mathrm{P}$ & $\mathrm{D}$ & $\mathrm{P}$ & $\mathrm{D}$ & $\mathrm{P}$ & $\mathrm{D}$ & $\mathrm{P}$ \\
\hline Antiinfectives for Systemic Use & 0 & 0 & 1 & 6 & 1 & 1 & 3 & 9 & 3 & 16 \\
\hline Antineoplastic and Immunomodulating Agents & 3 & 3 & 10 & 10 & 12 & 12 & 40 & 55 & 54 & 80 \\
\hline Dermatologicals & 0 & 0 & 1 & 1 & 0 & 0 & 2 & 3 & 2 & 4 \\
\hline Sensory organs & 0 & 0 & 1 & 1 & 0 & 0 & 0 & 0 & 1 & 1 \\
\hline Systemic Hormonal Preparations, excl. sex hormones and insulins & 1 & 1 & 2 & 3 & 1 & 2 & 3 & 5 & 4 & 11 \\
\hline Blood and Blood Forming Organs & 5 & 5 & 12 & 29 & 6 & 7 & 22 & 28 & 29 & 69 \\
\hline Cardiovascular System & 0 & 0 & 0 & 0 & 0 & 0 & 2 & 2 & 2 & 2 \\
\hline Genito Urinary System and Sex Hormones & 1 & 2 & 1 & 1 & 4 & 4 & 2 & 2 & 6 & 9 \\
\hline Musculo-Skeletal System & 0 & 0 & 3 & 7 & 2 & 2 & 4 & 6 & 5 & 15 \\
\hline Nervous System & 1 & 1 & 0 & 0 & 0 & 0 & 2 & 2 & 3 & 3 \\
\hline Respiratory System & 0 & 0 & 1 & 1 & 0 & 0 & 3 & 3 & 4 & 4 \\
\hline Alimentary Tract and Metabolism & 2 & 3 & 8 & 14 & 7 & 8 & 18 & 32 & 26 & 57 \\
\hline Various & 0 & 0 & 0 & 0 & 0 & 0 & 1 & 1 & 1 & 1 \\
\hline Total & 13 & 15 & 40 & 73 & 33 & 36 & 102 & 148 & 140 & 272 \\
\hline
\end{tabular}

Source: Author's elaboration. Legend: D-Drug; P-Product.

Although there are 140 registered drugs distributed across 272 products, $72.9 \%$ of these have been approved in the last five years. Three classes represent $77.9 \%$ of all drugs-Antineoplastic and Immunomodulatory Agents (38.6\%), Blood and blood organ formation (20.7\%) and Alimentary tract and metabolism (18.6\%), distributed in 75 or $7 \%$ of medicines $(29.4 \%, 25.4 \%, 21.0 \%)$, respectively. In turn, anti-infectives for systemic use and drugs used in the genitourinary system have the highest drug/medication ratio, approximately one to three.
Of the 277 products in the sample, 56 were authorized in 2019; 35 in 2018; 30 in 2017; 10 in 2016; 17 in 2015; 11 in 2014; 4 in 2013; 9 in 2012; 5 in 2011; 7 in 2010; 14 in 2009; 8 in 2008; 4 in 2007; 9 in 2006 and in 2005; 3 in 2004; 4 in 2003 and in 2002; 8 in 2001; 9 in 2000; 5 in 1999; and 16 between 1998 and 1988. In fig. 1, which represents the timeline, the products are identified by their regulatory categories, year by year.

Table 2: Organizes the regulatory categories next to the ATC classification level.

Table 2: Distribution of products according to the first ATC level and Anvisa regulatory category

\begin{tabular}{|c|c|c|c|c|c|}
\hline \multirow[t]{2}{*}{ ATC first-level classification } & \multirow[b]{2}{*}{ Absent } & \multicolumn{3}{|c|}{ Regulatory category } & \multirow[b]{2}{*}{ Total } \\
\hline & & Biological & New & Similar & \\
\hline Antiinfectives for Systemic Use & 1 & 12 & 1 & 2 & 16 \\
\hline Antineoplastic and Immunomodulating Agents & 2 & 73 & 4 & 1 & 80 \\
\hline Dermatologicals & 1 & 3 & 0 & 0 & 4 \\
\hline Sensory organs & 0 & 1 & 0 & 0 & 1 \\
\hline Systemic Hormonal Preparations, excl. sex hormones and insulins & 3 & 7 & 0 & 1 & 11 \\
\hline Blood and Blood Forming Organs & 5 & 48 & 9 & 7 & 69 \\
\hline Cardiovascular System & 0 & 2 & 0 & 0 & 2 \\
\hline Genito Urinary System and Sex Hormones & 0 & 7 & 0 & 2 & 9 \\
\hline Musculo-Skeletal System & 0 & 10 & 3 & 2 & 15 \\
\hline Nervous System & 0 & 3 & 0 & 0 & 3 \\
\hline Respiratory System & 0 & 4 & 0 & 0 & 4 \\
\hline Alimentary Tract and Metabolism & 3 & 47 & 5 & 2 & 57 \\
\hline Various & 0 & 1 & 0 & 0 & 1 \\
\hline Total & 15 & 218 & 22 & 17 & 272 \\
\hline
\end{tabular}

Source: Author's elaboration.

The records of biologicals intensified in the last $5 \mathrm{y}$ of the analysis, between 2014 and 2019 ( $n=131 ; 47.3 \%$ ), and the records of new and similar drugs intensified between 1999 and $2009(\mathrm{n}=14 ; 5.1 \%$ $\mathrm{n}=10 ; 3.6 \%$, respectively).

Among the 148 most recently approved biologicals, in the 2015-2019 period, 55 (67.6\%) were antineoplastic and immunomodulatory agents. In this class, authorizations were concentrated on monoclonal antibodies $(\mathrm{n}=23 ; 15.5 \%)$ and anti-TNF- $\alpha$ and non-anti-TNF- $\alpha(\mathrm{n}=10 ; 6.8 \%)$. With great application in the treatment of autoimmune diseases, in oncology and as markers of diagnostic tests, monoclonal antibodies usually end with the suffix "mabe," from English, monoclonal antibody, or "mABs" [11]. All biologicals approved by the comparability route were introduced in the last five years, in contrast to new biological products, where only $16.7 \%$ ( 3 drugs) were authorized.

The following table shows the price ranges of medicines in reais, per presentation.

Fifty-one medicines (18.4\% of the total) did not have their prices recorded on the CMED list [21]. Of these, 44 (86.3\%) were biological, of which eight were approved through comparability, 3 (5.9\%) were similar, 2 (3.9\%) were new, and 2 (3.9\%) did not have their record marked. Of the remaining 226 products, $108(47.8 \%)$ had prices in reais less than $1,000,92(40.7 \%)$ had prices between $R \$ 3,000$, and 10,000 and $26(11.5 \%)$ had prices above $\mathrm{R} \$ 10,000$.

Biological medicines are the most numerous and expensive. Of the 178 products registered with the CMED, $26(14.6 \%)$ are priced over 10,000 reais. Five are classified in the ATC with medications from the alimentary tract and metabolism, all of them registered since 2017. The most expensive enzyme (Alpha-Asphotase) indicated for hypophosphatasia (HPP) of perinatal/infantile and juvenile-onset costs almost 350 thousand reais. It is also worth mentioning the price of 130 thousand reais for two other drugs, Alfacerliponase and Teduglutida, for the treatment of neuronal ceroid lipofuscinosis type 2 (CLN2) and short bowel syndrome (SCI), respectively which are dependent on parenteral support. Of the products in the price range of 10,000 to 50,000 reais, 14 are antineoplastic, monoclonal antibodies, and immunosuppressant's, all registered since 2014.

The other three categories, new, similar, and absent, have very comparable characteristics, and no drugs among them are priced above $\mathrm{R} \$ 10,000$. For these three categories, only antineoplastic 
agents have prices ranging between 3,000 and 10,000 reais. Most products are in the lowest price range, below 200 reais, approximately $40 \%$ for those considered new and absent and $29 \%$ for similar products.

Table 3: Drug prices according to the categories analyzed

\begin{tabular}{|c|c|c|c|c|c|}
\hline \multirow[b]{2}{*}{ Price (R\$) } & \multicolumn{5}{|c|}{ Regulatory category } \\
\hline & Similar & Biological & New & Absent & Total \\
\hline $0-200$ & 4 & 35 & 9 & 5 & 53 \\
\hline $200-500$ & 3 & 18 & 4 & 1 & 26 \\
\hline $500-1000$ & 5 & 18 & 3 & 3 & 29 \\
\hline $1.000-3.000$ & 1 & 41 & 4 & 1 & 47 \\
\hline $3.000-10.000$ & 1 & 40 & 2 & 2 & 45 \\
\hline $10.000-50.000$ & 0 & 20 & 0 & 0 & 20 \\
\hline $50.000-150.000$ & 0 & 5 & 0 & 0 & 5 \\
\hline$>150.000$ & 0 & 1 & 0 & 0 & 1 \\
\hline NI & 3 & 44 & 2 & 2 & 51 \\
\hline Total & 17 & 222 & 24 & 14 & 277 \\
\hline
\end{tabular}

Source: Author's elaboration. No information=NI

\section{DISCUSSION}

The collected data show numbers and records that are difficult to interpret. A first difficulty concerns registering with Anvisa. Although RDC $n{ }^{\circ} 55 / 2010$ defines only two regulatory categories, new and biological, the registered products include a group of similars and another group without classification $[17,22]$. What further aggravates categorization is that for Anvisa itself, organic products are a category for which the registration of similar products is not allowed $[8,23]$ although 17 of 277 inputs (6.1\%) had this classification. Unfortunately, this is not a new problem. When analyzing the new drugs registered in Brazil more than a decade ago, Gava and collaborators [23] suggested that Anvisa implement better disclosure of practices related to health registration. This information, associated with the characteristics of registration approval and commercialization itself, provides important elements for prescribers, patients, and industry [24].

Another barrier to registration is the date of the first authorization that is the most recent or the revalidation of the registration. For a drug whose marketing was approved in 2014 and whose validity is five years, the date that appears will be the revalidation date of 2019., It is necessary to check the expired approvals of the input to search the year of the first registration.

The highest concentration of approvals occurred between 1999 and 2009 , although the definition of new biologicals appeared in 2010 together with RDC $n{ }^{\circ} 55 / 2010$,. In contrast, of the 222 biologicals approved since 1999, more than $65 \%$ of authorizations have occurred in the past five years.

Despite the registration problems, perhaps the most important issue is assessing the authorization process for biological agents by individual development or comparability. Only the latter ensures that these drugs can be considered equivalent to the biosimilars on the international market. The first route would make products a category more like similars on the non-biologic market. Although Anvisa considers this instrument an interesting possibility for making medicines available, it practically does not exist in the international scenario [17].

The National Administration of Medicines, Food and Medical Technology (ANMAT), an Argentine health regulatory agency, published ANMAT Regulation No. 7729/2011, where the comparability exercise must be carried out so that the drug to be registered demonstrates the quality that is very similar to the reference drugs [25]. The National Medicines Agency of Chile (ANAMED) developed Technical Norm 170/2014 [26], created based on international criteria and recommendations of the World Health Organization (WHO), for the submission and evaluation of biopharmaceutical dossiers. This regulation provides tools for the authorization of biosimilar products to guarantee the same safety and efficacy as innovative biological medicines [26].

In Colombia, the abbreviated strategy for comparability of Decree $1782 / 2014$ [27], although it follows this rationality, is not exactly equivalent to a classic shortened mechanism. According to the
Colombian health authority, the National Institute for the Monitoring of Medicines and Foods (INVIMA), the use of the name "shortened route" has no less stringent connotations in the evaluation or acceleration of review time by the agency because a competitor must support its registration application using the available information on the safety and efficacy of a product, without exposing animals or humans to unnecessary experiments. Reduced procedures are used at most health agencies to register synthetic generics [28]. Anvisa uses this path, following the same arguments [17].

Corroborating this view, Gavíria, and collaborators [28] state that the two possible routes for registering a biosimilar medicine follow international standards: a complete dossier with robust preclinical and clinical evidence of safety and efficacy and an abbreviated dossier, with a demonstration of similarity to an originating product that is sufficient to justify confidence in the sender's safety and effectiveness research. According to the authors, the consensus approach for the reduced dossier of a biosimilar medicine involves rigorous comparison, proceeding through comparative analytical and functional characterization for preclinical and clinical tests.

This position, however, is not unchallenged. Lietzam [29] states that the shortened path for the registration of biosimilars adopted in Colombia would correspond, in reality, to a third technique since its methods are different from those adopted in the international market because they are less careful. In Colombia, there would be fundamental differences since the succinct comparability procedure ("fast track") would not correspond to any other model of drug approval in Europe or the United States. The path of the complete dossier and the path of comparability would correspond to the new biological and the biosimilar in Europe and the United States.

The indications for the use of approved biologicals in Brazil are concentrated on antineoplastic and immunomodulatory agents (80), primarily for mABs (23), blood preparations (69), and metabolism (57). Biopharmaceutical approvals are usual for rheumatic diseases, cancers, and autoimmune diseases [30].

This picture of authorizations in Brazil is similar to that in the rest of the world, as long as the route used is not considered. The first mAB therapeutic product was commercialized in 1986. Since then, this class of biopharmaceutical products has grown significantly. According to Harston [31], of the 59 biosimilars approved by the EMA, 26 were mABs, that is, $44 \%$. Insulins, blood products, and hormones complete the picture of EMA biosimilar approvals.

Therapies based on biological products consist of therapeutic innovations considered a priority and, thus, represent a significant therapeutic advance in the face of the already existing options [32]. However, the high cost of treatment with these agents is a barrier to access, even in the most developed countries [33].

In Brazil, a biological (which has used either of the two development pathways) is not always cheaper than the reference medicine. Medicines with prices above R \$50,000.00 are biologicals approved 
by individual development and are two to ten times more expensive than those accepted by comparability. This situation distorts the national market when the international situation is considered.

Several authors indicate the possibility of reducing prices and costs for health systems through the inclusion of biosimilar medicines [2, 34-36]. While Europe sells biosimilars with discounts of $20 \%$ to $35 \%$ concerning the price of reference products [14], in Spain, they cost $30 \%$ less than the original products, as agreed by Decree [37, 38]. German social insurance receives discounts of $10 \%$ for medicines with the same manufacturing process. As a counterpoint to what occurs in these nations, we find in Brazil a scenario [14], similar to that found in other emerging countries [39]: companies producing biosimilars avoid trading in countries with low price policies and low refund rates to preserve projected sales prices.

This work has some limitations, which requires caution when interpreting its findings. Recent approvals for registration, noncommercialization of the product, or even the absence of distributors may be behind the absence of a drug in the market, indicated here by the absence of price on the CMED list [21]. Price comparisons between originals and biosimilars were made to the extent that they coincided in presentation, concentration, and formulation. An ideal price analysis would control all these characteristics.

It would be important to have data on the sale and market share of these inputs available to researchers from diverse institutions, whether in Brazil or abroad.

The use of official databases with predetermined structure and without information gaps that limit evaluations based on the data should be considered. In addition to the great amount of information that could potentially be generated for health services, the scarcity of studies of this nature and the difficulty of analyzing information from databases with so many particularities is highlighted.

\section{CONCLUSION}

The main objective of this study was to map the characteristics and prices of biological and biosimilar medicines marketed in Brazil. According to Anvisa [15], biological medicines showed the highest growth rate in sales between 2015 and 2017, accounting for $22 \%$ of total sales in the last year. In contrast, it was the class of drugs with the lowest number of units sold.

In this study, there was no trend, but the prices of the original products, for most of the inputs, are lower than those of biosimilars.

In the last five years, biosimilars or biologicals approved employing comparability have obtained their registration with Anvisa and started to be commercialized in the country, but their impact is still unknown. This market seems to follow the movement of generic drugs, with an increased supply of products at lower prices that have a small effect on the price levels of reference products. It is expected that the optimism present in international literature will replicate here and that biosimilars will cause a decrease in the prices of innovative biologicals.

\section{ACKNOWLEDGMENT}

RLA's family, as well as friends, relatives, and colleagues at IMS/UERJ, for all the support offered during the period of his illness. Renata was made of determination and joy. We thank Mel M. M. Vianna for helping with the database and Fernando Nagib for the endless discussions on regulation.

We would like to thank Federal Fluminense University (UFF) and the PROPPI for the PIBIC scholarship that was granted to TPC, a student at the School of Pharmacy.

\section{FUNDING}

There are no disclosures of a declarable nature, financial of our editorial support.

\section{AUTHORS CONTRIBUTIONS}

RLA, GBGM, CMMV contributed in the following aspects: conception, planning, writing, analysis, interpretation, review, and writing of the final work. FA and TPC contributed in the following aspects: analysis, interpretation and review of the final work.

\section{CONFLICT OF INTERESTS}

The authors declare that there is no conflict of interest concerning the content of the present study.

\section{REFERENCES}

1. Grampp G, Ramanan S. Managing unexpected events in the manufacturing of biologic medicines. BioDrugs 2013;27:30516.

2. Buske C, Ogura M, Kwon HC, Yoon SW. An introduction to biosimilar cancer therapeutics: definitions, the rationale for the development and regulatory requirements. Futur Oncol 2017;13:5-16.

3. Tanaka RL, Amorim MCS. The market and the possibilities of the biopharmaceutical industry in Brazil. Rev Fac Ciencias Med Sorocaba 2014;16:86-92.

4. National Health Surveillance Agency (Anvisa). Biological Medicines for the Treatment of Rheumatoid Arthritis. BRATSBoletim Brasileiro de Avaliaçao de Tecnologias em Saude. Brasilia; 2012.

5. Martell RE, Sermer D, Getz K KK. Oncology drug development and approval of systemic anticancer therapy by the U. S. Food and drug administration. Oncologist 2013;18:104-11.

6. Garcia R, Araujo DV. The regulation of biosimilars in Latin America. Curr Rheumatol Rep 2016;18:1-8.

7. Renganathan R, Vijayabanu C, Srinivasakumar V, Vijay Anand V. Pharmaceutical pricing policy and control: Indian perspective. Asian J Pharm Clin Res 2016;9:305-8.

8. Gomes EBP, Rosseto R, Pinheiro L, Hasenclever L, Paranhos J. Development of biosimilars in Brazil. Fronteiras 2016;5:31-42.

9. Casey D. Key strategic factors for stakeholders in the current global biosimilar market. Drug Discovery Today 2016;21:208-11.

10. Bernal Camargo DR, Gaitan Bohorquez JC, Leon Robayo EI. Biosimilar medicines in colombia: an approach from the informed consumption. Rev Ciencias Salud 2018;16:311-39.

11. Interfarma. Pharmaceutical research industry association understanding biological medicines. Interfarma: Pharmaceutical Research Industry Association. Sao Paulo; 2012.

12. Ruiz R, Strasser Weippl K, Touya D, Herrero Vincent C, Hernandez Blanquisett A, St Louis J, et al. Improving access to high-cost cancer drugs in Latin America: Much to be done. Cancer 2017;123:1313-23.

13. Belloni A, Morgan D, Paris V. Pharmaceutical expenditure and policies: past trends and future challenges, OECD Health Working Papers. OECD Publishing; 2016.

14. Farhat F, Torres A, Park W, de Lima Lopes G, Mudad R, Ikpeazu $\mathrm{C}$, et al. The concept of biosimilars: from characterization to evolution-a narrative review. Oncologist, 2018;23:346-52.

15. Agencia Nacional de Vigilância Sanitaria (Anvisa). Pharmaceutical Market Statistical Yearbook; 2018.

16. Berkowitz SA, Engen JR, Mazzeo JR, Jones GB. Analytical tools for characterizing biopharmaceuticals and the implications for biosimilars. Nat Rev Drug Discovery 2012;11:527-40.

17. National Health Surveillance Agency (ANVISA). Rdc n ○5/2010. Brasil: Publicada no DOU n ${ }^{\circ} 241$, de 17 de dezembro de 2010; 2010. p. 26.

18. Interfarma. Pharmaceutical Research Industry Association. Biological and biosimilar medicines and their regulatory standards. Primer for patients. $1^{\text {a }}$. São Paulo: Interfarma. Pharmaceutical Research Industry Association; 2013. p. 1-20.

19. National Health Surveillance Agency (Anvisa). Consultation of the medication registry. Available from: https://consultas. anvisa.gov.br/\#/medicamentos/ [Last accessed on 10 Mar 2020]

20. World Health Organization (WHO) Collaborating Centre for Drug Statistics. ATC/DDD Index; 2020. Available from: https://www.whocc.no/atc_ddd_index/?code=L04AB02 [Last accessed on 28 Dec 2019]

21. Medicine Market Regulation Chamber (CMED). Maximum Prices of Medicines by Active Principle. Vol. 796. Brasilia; 2019. 
22. National Health Surveillance Agency (Anvisa). Regularizacao de Produtos-Medicamentos. Registro de Medicamentos Similares; 2020. Available from: http://portal.anvisa.gov.br/registros-eautorizacoes/medicamentos/produtos/medicamentossimilares/registro [Last accessed on 05 Feb 2020]

23. Gava CM, Bermudez JAZ, Pepe VLE. New drugs registered in Brazil: Can they be considered as a therapeutic advance? Cience Saude Coletiva 2010;15(Suppl 3):3403-12.

24. MarketResearch.com. The Growing Pharmaceuticals Market: Expert Forecasts and Analysis. Rockville MD (US); 2019. Available from: https://blog.marketresearch.com/the-growing-pharmaceuticals-market-expert-forecasts-and-analysis

25. National Administration of Medicines, Food and Medical Technology (ANMAT); Disposal n ${ }^{\circ} 7729 / 2011$. Argentina; 2011. [Last accessed on 18 Mar 2019]

26. Ministerio Salud I. Technical standard 170 of sanitary registration of biotechnological products derived from recombinant techniques; 2014. p. 1-27.

27. Colombia M de Sy PS. Decree n ${ }^{\circ} 1782$ de 2014 . Colombia; 2014. p. 713-24.

28. Gaviria A, González CPV, Munoz CG, Morales AA. The biotech drug regulation debate: colombia in the international context. Rev Panam Salud Publica/Pan Am J Public Heal 2016;40:40-7.

29. Lietzan E. Carta Al Editor: How Colombia's biosimilar regulation departs from international norms. Rev Panam Salud Publica; 2017. p. 41

30. Aggarwal SR. What's fueling the biotech engine-2012 to 2013. Nat Biotechnol 2014;32:32-9.

31. Harston A. How the U. S. compares to europe on biosimilar approvals and products in the pipeline. Rothwell Figg; 2019.
Available from: https://www.biosimilarsip.com/2019/05/ 07/how-the-u-s-compares-to-europe-on-biosimilar-approvalsand-products-in-the-pipeline-4/ [Last accessed on 05 Mar 2019]

32. Beaver JA, Howie LJ, Pelosof L, Kim T, Liu J, Keegan P, et al. A 25 $\mathrm{Y}$ experience of us food and drug administration accelerated approval of malignant hematology and oncology drugs and biologics a review. JAMA Oncol 2018;4:849-56.

33. McCamish M, Woollett G. Worldwide experience with biosimilar development. MAbs 2011;3:212-20.

34. Cornes P. The economic pressures for biosimilar drug use in cancer medicine. 2012;7Suppl 1:S57-67.

35. Experience I, Potential F. Biosimilar cost savings in the United States initial experience and future potential short abstract roadmap the cost savings potential of biosimilars. Rand Heal Q 2019;7:3-20.

36. Castaneda Hernandez G, Szekanecz Z, Mysler E, Azevedo VF, Guzman R, Gutierrez M, et al. Biopharmaceuticals for rheumatic diseases in Latin America, Europe, Russia, and India: Innovators, biosimilars, and intended copies. Jt Bone Spine 2014;81:471-7.

37. Rovira J, Espin J, Garcia L, Labry AO De. The impact of biosimilars' entry in the EU market; 2011.

38. BOE Num 98. Real-Decreto ley 16/2012, de 20 de abril, of urgent measures to guarantee the sustainability of the National Health System and improve the quality and safety of its services. Espanha: BOE Num 98; 2012.

39. Shaik R, Muragundi PM. Evaluation of price disparity among generic medicines in India. Asian J Pharm Clin Res 2018;11:466-8. 